\title{
Um Estudo Observacional sobre as Adaptações ao Trabalho Remoto no contexto da Pandemia de COVID-19
}

\author{
Diego A. S. Lisbôa, Thayssa A. da Rocha, Letícia S. Machado, Clara M. Caldeira, \\ Cleidson R. B. de Souza
}

\author{
Universidade Federal do Pará - Brasil \\ diegolisboa@ufpa.br, thayssa.rocha@icen.ufpa.br, \\ leticia.smachado@gmail.com, cmarque@iu.edu, cleidson.desouza@acm.org
}

\begin{abstract}
Resumo. As necessidades de isolamento social adotadas para conter a disseminação da pandemia da COVID-19 levaram muitas empresas a adotar o trabalho remoto de maneira obrigatória e não planejada. Esta transição repentina ao trabalho remoto de casa tem causado profundas mudanças nas relações pessoais e profissionais. Neste artigo, apresentamos os resultados de um estudo observacional qualitativo sobre as adaptações realizadas nas atividades do processo de software de uma coordenação de desenvolvimento de software de uma universidade brasileira. Estas adaptações visavam apoiar a transição para o trabalho remoto durante a pandemia. Elas foram analisadas com base no framework teórico de Olson e Olson para colaboração distribuída. As motivações para as adaptações feitas e os desafios observados também são apresentados. A partir destes resultados, o artigo apresenta recomendações para facilitar a adaptação ao trabalho remoto.
\end{abstract}

\section{Introdução}

Sistemas colaborativos são essenciais para diversos profissionais, inclusive para engenheiros de software. De fato, desenvolver software é uma atividade social com tarefas centradas nos indivíduos e seus relacionamentos, interações e colaborações. A importância da interação entre os engenheiros de software é explicitada no primeiro valor do manifesto ágil: "indivíduos e interações mais que processos e ferramentas". Enquanto isto, o terceiro valor ágil ressalta a importância da colaboração entre os membros: "colaboração com o cliente mais que negociação de contratos" (AGILE MANIFESTO). Isso significa que desenvolver software não depende apenas de aspectos técnicos, mas também das interações entre os indivíduos que realizam as atividades.

Em 2020, o mundo inteiro foi surpreendido com a pandemia da COVID-19. Para lidar com a mesma, diversas ações foram necessárias, especialmente a necessidade de distanciamento social com a necessidade de trabalhadores permanecerem em suas casas. As restrições impostas pela pandemia têm causado profundas mudanças nas relações de trabalho e na forma como esse trabalho é desenvolvido: muitas empresas foram obrigadas a aderir, em curto prazo, ao trabalho remoto. Essa transição repentina e obrigatória impactou a vida pessoal de muitos indivíduos e suas dinâmicas familiares (MACHADO, et al., 2020). Segundo RALPH et al. (2020), durante a pandemia as pessoas estão trabalhando remotamente, mas, não em um escritório ou ambiente preparado para isto, e sim de suas camas, mesas da cozinha, sofás e com todo contexto familiar (filhos, esposas/maridos, animais de estimação, etc) propícios a interrupções e também sem as redes de apoio como diaristas e escolas. 
Embora a literatura de CSCW possua diversos estudos relacionados ao trabalho remoto (OLSON e OLSON, 2000; OLSON et al., 2008; BJØRN et al., 2014), ainda há uma quantidade limitada de publicações que dão enfoque no trabalho remoto durante crises, como a pandemia de COVID-19, simplesmente porque o mundo não tinha sido acometido por uma situação similar desde o surgimento da rede mundial de computadores (RALPH, et al., 2020). O impacto da pandemia exigiu rápida adaptação para uma nova forma de trabalho usando ferramentas colaborativas que permitem o compartilhamento de documentos, trabalho síncrono e videoconferências. Neste contexto, a escala de adoção e uso de tais ferramentas ultrapassou rapidamente o que sabemos sobre sistemas colaborativos.

Este artigo descreve as adaptações realizadas nas atividades do processo de software de uma coordenação, chamada de COTIC, de uma universidade brasileira e sua transição ao trabalho remoto durante a pandemia da COVID-19. As adaptações, suas motivações, os desafios encontrados e as recomendações de melhoria, são apresentadas usando o framework para colaboração distribuída de $\operatorname{OLSON}$ e $\operatorname{OLSON}(2000,2008)$.

Este artigo está organizado como segue. A seção 2 detalha o framework de colaboração distribuída e é seguida pela metodologia usada neste trabalho. As seções $4 \mathrm{e}$ 5 detalham o trabalho antes e depois da pandemia. A seção 6 apresenta a análise das adaptações conforme as dimensões de colaboração distribuída. Na seção 7 é apresentada a discussão dos resultados enquanto a seção 8 descreve as recomendações para as organizações. Finalmente, a seção 9 apresenta conclusões e trabalhos futuros.

\section{O Framework de Colaboração Distribuída}

A literatura de CSCW tem inúmeros exemplos de estudos sobre trabalho em contextos remotos, porém, este estudo utilizou o framework de colaboração distribuída de OLSON e OLSON (2000, 2008). Este framework descreve cinco conceitos principais, associados ao sucesso do trabalho remoto: entendimento comum, acoplamento de trabalho, prontidão para colaboração, prontidão para tecnologia de colaboração e gestão organizacional. Este framework foi identificado baseado em diversos anos de pesquisa sobre colaboração entre equipes distribuídas. Assim, ele pode ser usado para "avaliar" o preparo de uma equipe com membros distribuídos para lidar com os desafios da colaboração distribuída.

Segundo BJØRN et al. (2014), o entendimento comum refere-se ao conhecimento que as pessoas compartilham entre si o que permite entender as suposições uns dos outros; o acoplamento de trabalho refere-se à interdependência entre as tarefas realizadas pelos colaboradores; a prontidão para colaboração diz respeito a quanto os participantes das equipes distribuídas estão prontos para se envolver em atividades de colaboração, apesar da distância; a prontidão para tecnologia de colaboração refere-se às dificuldades enfrentadas na adaptação, adoção e inserção de tecnologias para colaboração; e, finalmente, a gestão organizacional refere-se às práticas e políticas pelas quais as atividades de gestão contribuem, ou não, para a colaboração à distância. Estes cinco conceitos que compõem o framework de OLSON e OLSON, serão considerados na seção 6 como uma lente analítica na análise das adaptações da colaboração distribuída no contexto da pandemia da COVID-19. 


\section{Metodologia}

\subsection{Contexto Organizacional}

A COTIC tem como principal objetivo o desenvolvimento de sistemas de software requisitados por uma das pró-reitorias, além da sustentação dos sistemas já existentes em seu portfólio. Especificamente, o primeiro autor deste artigo é funcionário da COTIC, assim, ele teve acesso aos dados do processo de software antes e durante a pandemia.

No período da pesquisa, o time da COTIC era composto por dez colaboradores: dois servidores públicos e oito bolsistas. A composição dos membros do time, baseada nos papéis do framework Scrum (SCRUM GUIDE), contou com um Scrum Master (SM), um Product Owner (PO) e o Scrum Team, que são os membros responsáveis pela implementação do produto. Também interagiram com o time membros externos à organização, como especialistas das áreas de negócios, chamados de stakeholders.

\subsection{Coleta e Análise de Dados}

A metodologia utilizada consiste na pesquisa empírica qualitativa, através da observação participativa do processo de trabalho do time da COTIC. O período de coleta de dados abrange desde o início do período de isolamento social, em meados de março, até dezembro de 2020. Neste intervalo, o time da COTIC executou 5 projetos, sendo 4 relacionados a sistemas legados, com demandas de manutenção evolutiva, e 1 projeto novo, que iniciou logo após o começo da pandemia, tendo todas as suas etapas executadas com o time trabalhando remotamente.

A observação participativa permite que o pesquisador observe e compreenda os acontecimentos, as situações e os participantes do estudo enquanto age com eles (FINO, 2003). Assim, o primeiro autor participou diariamente da rotina de trabalho da COTIC, atuando como SM, com a responsabilidade de garantir que o processo ágil fosse seguido, facilitando reuniões, acompanhando atividades e removendo impedimentos. Nesse sentido, a coleta de dados foi realizada com base na observação participativa da rotina de trabalho do time, bem como através das interações entre o time e com os stakeholders. As notas de campo foram elaboradas com base nos logs de conversas das ferramentas de comunicação; atividades documentadas em ferramentas de gestão de projetos colaborativas; artefatos armazenados no repositório compartilhado; feedback dos participantes nas reuniões de retrospectiva (SCRUM GUIDE) e em outras reuniões. Durante o período de coleta de dados, essa documentação, de acesso restrito, foi compartilhada apenas entre os autores desta pesquisa para análise dos dados.

Os dados foram analisados da seguinte forma. Inicialmente, o primeiro autor selecionou as notas de campo que tinham relação com o framework de OLSON e OLSON. Em seguida, os dois primeiros autores relacionaram os dados obtidos nas notas de campo, de acordo com cada uma das cinco dimensões do framework de colaboração distribuída sob orientação do último autor. Posteriormente, dois outros autores revisaram a análise para evitar um possível viés. A análise visava entender se as adaptações do processo de software por causa da pandemia atendiam as recomendações do framework de OLSON e OLSON. Este processo colaborativo de análise dos dados, foi realizado através de reuniões online e usando documentos compartilhados em formato Word. 


\section{O Processo de Software da COTIC Antes da Pandemia}

O processo de desenvolvimento de software da COTIC é composto por sete etapas. Uma versão original das suas etapas pode ser encontrada em MONTEIRO e OLIVEIRA (2019), porém este artigo considera a versão atualizada, que inclui adequações nas etapas iniciais, referentes às atividades conforme Figura 1 (Durante a Pandemia): Construir Modelo Abrangente, Planejar Releases e Construir Backlog do Produto. Uma visão geral deste modelo é apresentada na Figura 1 (Antes da Pandemia).

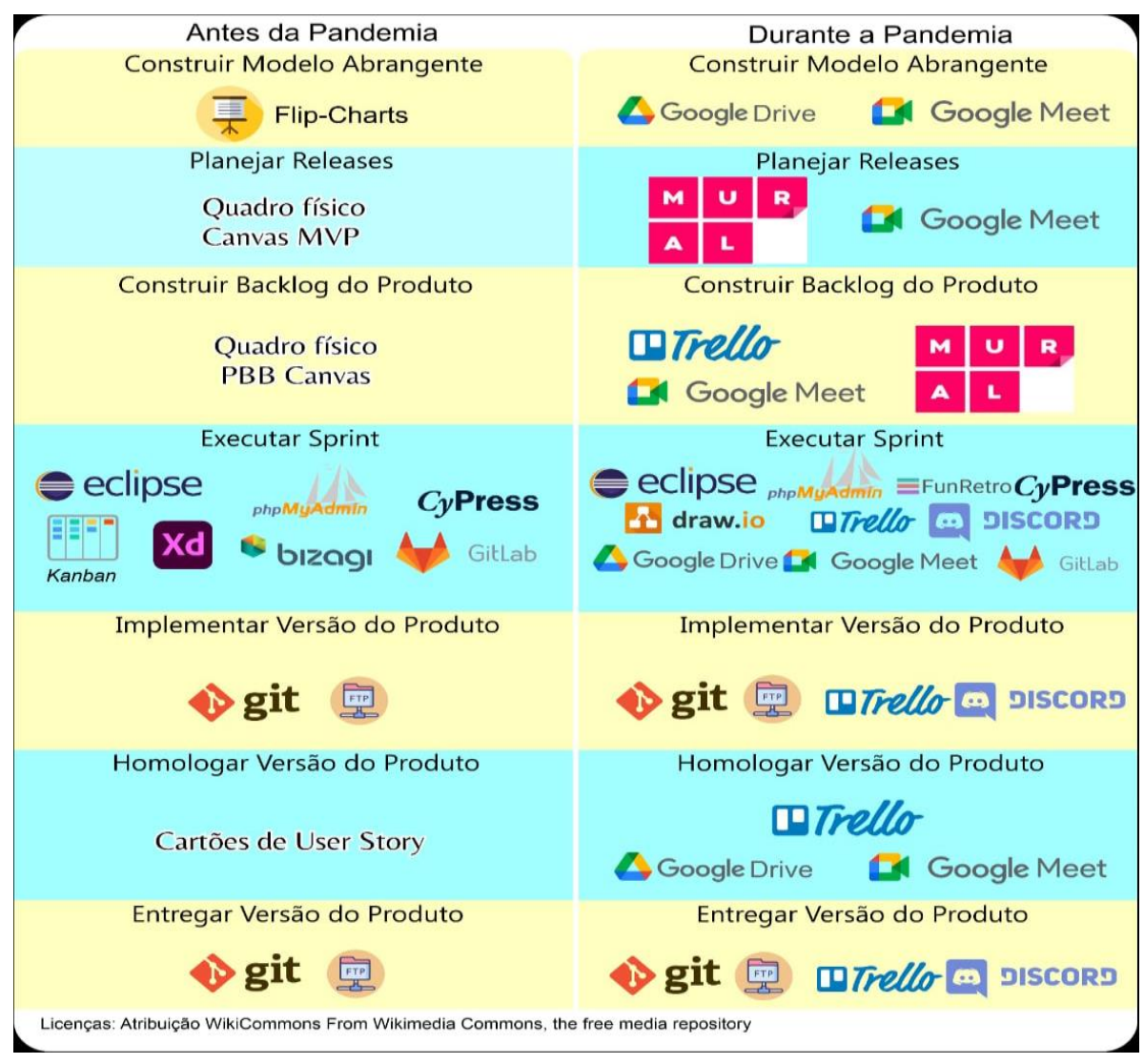

Figura 1. Comparativo entre as ferramentas utilizadas antes e durante a pandemia de COVID-19.

4.1 Construir Modelo Abrangente: esta atividade visa alinhar com os stakeholders as ideias referentes ao produto mínimo viável (em inglês - minimum viable product - MVP) a ser construído e seus incrementos. Todos os membros do time participam desta etapa e são utilizadas ferramentas como quadro branco, flip-chats e post-it's.

4.2 Planejar Releases: tem o objetivo de definir a sequência pela qual as funcionalidades do produto serão entregues. Todo o time participa desta atividade e a principal ferramenta utilizada é um quadro físico denominado Canvas MVP.

4.3 Construir Backlog do Produto: tem por objetivo criar e elaborar um backlog do produto (SCRUM GUIDE) efetivo e colaborativo. Todos participam desta atividade e a principal ferramenta utilizada é novamente um quadro físico denominado PBB Canvas.

4.4 Executar Sprint: visa a execução das sprints de construção do produto. As principais ferramentas utilizadas são: Cartão de User Stories em post-its; quadro físico Kanban para gestão visual do andamento do trabalho; ferramentas Adobe XD e Bizagi para 
prototipação e modelagem; ferramentas Eclipse IDE e PHPMyAdmin para desenvolvimento de software e gerenciamento de banco de dados; e, finalmente, as ferramentas GitLab para controle de versões e Cypress para testes automatizados.

4.5 Incrementar Versão do Produto: tem como objetivo integrar o código das User Stories desenvolvidas, para disponibilização da versão em homologação. O responsável pela execução desta atividade é o Scrum Team e a ferramenta utilizada é o GIT-FTP.

4.6 Homologar Versão do Produto: visa apresentar uma nova versão do produto de software para o Product Owner ((SCRUM GUIDE), em ambiente de homologação, para avaliação. Todo o time participa e são utilizados os cartões de User Stories.

4.7 Entregar Versão do Produto: esta atividade disponibiliza a nova versão do produto para os usuários finais em ambiente de produção. O responsável pela execução desta atividade é o Scrum Team. A ferramenta utilizada é o GIT-FTP.

A descrição em alto nível do processo de desenvolvimento de software da COTIC permite observar a realização de várias atividades de coordenação e alinhamento de forma presencial com todo o time, bem como a utilização de ferramentas que exigem a presença de todos em um mesmo espaço físico compartilhado. Por exemplo, o planejamento das releases requer a construção colaborativa de um artefato, utilizando-se um quadro físico e post-its. Com a pandemia, este processo foi modificado conforme descrito a seguir.

\section{O Processo de Software da COTIC Durante a Pandemia}

Com a migração repentina para o trabalho remoto, adaptações foram necessárias para a execução do processo de desenvolvimento de software existente. Como funcionário da COTIC, o primeiro autor deste trabalho foi responsável por adaptar este processo (Figura 1, Durante a Pandemia) mantendo as práticas ágeis de desenvolvimento de software já adotadas, porém através do trabalho remoto. Além disso, optou-se também por flexibilizar a carga horária do time gerenciando a alocação de turnos de trabalho usando uma planilha compartilhada no Google Drive. As atividades do processo e os responsáveis por sua execução se mantiveram inalterados: as mudanças ocorreram apenas na utilização de ferramentas colaborativas para auxiliar a execução das atividades. Durante as atividades Construir Modelo Abrangente, Planejar Releases, Construir Backlog do Produto e Homologar Versão do Produto, as reuniões entre os responsáveis pelas tarefas foram feitas por videoconferência através do Google Meet. Já a ferramenta Google Drive foi adotada para o compartilhamento de arquivos durante todo o processo.

Para as atividades Construir Modelo Abrangente, Planejar Releases e Construir Backlog do Produto, realizadas com a presença de stakeholders externos à COTIC, o tempo de duração das dinâmicas também precisou ser adaptado. Antes da pandemia, os stakeholders reservavam um período, ou até um dia inteiro, para execução dessas atividades. No entanto, com o início do trabalho remoto, surgiram dificuldades para interações cujas durações passavam de duas horas. Neste contexto, foi possibilitado ao Scrum Team a atuação fora do seu turno original, inclusive no período noturno.

Nas atividades de Construir Modelo Abrangente e Planejar Releases, com a limitação de utilização de quadros físicos, adotou-se a ferramenta Web Mural com o template de Lean Inception (CAROLI, 2018) para a gestão visual e digital dessas atividades, permitindo a colaboração simultânea de membros ao quadro virtual. 
Para a construção do Backlog do Produto, foi novamente utilizada a ferramenta Web Mural com o template do Product Backlog Canvas (AGUIAR and CAROLI, 2020), a fim de fazer a gestão visual das atividades. Além disso, a ferramenta Trello foi utilizada para organizar os itens do Product Backlog gerados nesta atividade. Esta ferramenta também foi utilizada durante a execução da Sprint. Para a comunicação interna entre os membros do time ágil, foi utilizada a ferramenta Discord, que permite utilização de voz por IP e a criação de canais de comunicação via texto, áudio e videoconferências. $\mathrm{Na}$ COTIC os canais são organizados por projeto, acrescidos dos canais de socialização e de apoio técnico e de negócios oferecendo acesso e livre contribuição em qualquer momento do dia de todos os membros internos da COTIC (SM, PO e Scrum Team). O canal de socialização, denominado \#topic-off, foi utilizado para conversas informais entre os membros do time ágil, com link de cursos e treinamentos, informativos sobre a pandemia da COVID-19 e assuntos gerais. Já os canais de apoio técnico e de negócios, denominados \#help-tecnico e \#help-negocio, eram utilizados para dúvidas técnicas e relativas ao entendimento às regras de negócios das User Stories, respectivamente. Todos os canais foram utilizados pelo time, sendo o \#topic-off o de maior frequência, principalmente para atualização das informações sobre a pandemia incluindo a vacina.

As atividades vinculadas à construção das histórias foram realizadas em pares, atribuídas na ferramenta Trello conforme as informações de disponibilidade da planilha do Google Drive já citada. Por outro lado, as reuniões de retrospectiva foram realizadas com o auxílio da ferramenta FunRetro que permite gestão visual da cerimônia, registro das informações dos participantes e organização do tempo de duração da reunião. Também se passou a utilizar outros recursos do GitLab, como a Wiki, para gestão do conhecimento: os membros do Scrum Team registravam os procedimentos padrões para execução de determinadas atividades, permitindo que colaboradores pudessem ter acesso a esse conteúdo, caso necessário.

Nas atividades de Incrementar e Entregar Versão do Produto, a comunicação entre o time foi realizada via Discord e a ferramenta Trello foi utilizada para indicar as User Stories que comporiam a versão. Os artefatos relevantes foram compartilhados via Google Drive, para que todos os envolvidos pudessem acessar e contribuir. Finalmente, na atividade de Homologar Versão do Produto, a ferramenta Trello foi utilizada para gerenciar as User Stories e eventuais mudanças, defeitos e melhorias.

\section{Resultados}

Para classificar as adaptações identificadas no processo da COTIC, foram utilizados os cinco conceitos para colaboração distribuída detalhados (ver seção 2). Cada um destes cinco conceitos é usado como uma "lente analítica" para explicar como as adaptações feitas podem auxiliar no processo de trabalho remoto durante a pandemia. Além disso, desafios da colaboração distribuída também foram observados e são relatados.

\subsection{Entendimento Comum}

6.1.1 Adaptações: Membros do time usaram recursos compartilhados (documentos, trello, etc) para documentar decisões e planejamentos - e conversas síncronas e assíncronas para discutir ideias, responder perguntas e sanar desentendimentos. Essas atividades em conjunto permitiram a construção e manutenção do entendimento comum. Devido ao cenário da pandemia, estas ferramentas configuraram como o único meio de comunicação possível, não tendo sido observado no período nenhum outro tipo de 
interação para promoção do entendimento comum entre a equipe, reforçando assim, a importância desse aspecto no contexto estudado. Como principais ferramentas de comunicação incluem: Google Meeting para reuniões remotas de áudio e videoconferências com os stakeholders; Discord para reuniões em canais de texto, áudio e videoconferências entre os membros do Scrum Team. Também foram utilizadas ferramentas para gestão visual das dinâmicas ágeis com recursos para facilitação de colaboração entre os participantes, com destaque para: Web Mural para as dinâmicas colaborativas remotas de Lean Inception e Product Backlog Building; Trello para gestão das tarefas; e FunRetro para as dinâmicas de retrospectiva ao final de cada Sprint.

6.1.2 Framework Analítico: conforme uma ampla gama de ferramentas colaborativas surge, encontram-se maneiras de utilizá-las para atingir os objetivos do time (OLSON e OLSON, 2000). Dessa forma, torna-se necessária a adequação do processo para utilização de ferramentas que proporcionem rápidos feedbacks e compartilhamento de informações, contribuindo para um maior entendimento comum entre os membros.

6.1.3 Desafios: Durante alguns momentos, a comunicação entre os membros do time ágil era feita por canais de voz (ferramenta Discord), ou através de ferramentas de videoconferência, porém com as câmeras desligadas. Nesse contexto, foram observados maiores desafios para a comunicação, que demandou maior esforço para estabelecer o entendimento comum, quando comparado às oportunidades de interação presencial. As demais ferramentas não apresentaram desafios relevantes no processo de favorecer o entendimento comum, pois ofereceram possibilidade de troca de informação com imagens, texto e links.

\subsection{Acoplamento do Trabalho}

6.2.1 Adaptações: Os turnos de trabalho passaram a ser mais flexíveis, permitindo interações de maneira mais livre, conforme disponibilidades na planilha compartilhada de horários. Assim, não houve mudanças no acoplamento para execução de tarefas em pares, mas sim na facilidade para interação entre membros de turnos diferentes.

6.2.2 Framework Analítico: o trabalho acoplado faz com que os participantes remotos tenham interações com mais frequência (BJØRN et al., 2014). Assim, a prática de execução de tarefas pareadas permitiu minimizar a curva de aprendizagem dos membros do time, seja para inspeção em tempo real do trabalho realizado ou para feedback imediato. Trabalho acoplado, e consequentemente interações mais frequentes, também possibilitaram colaboração e compartilhamento de conhecimento entre os membros.

6.2.3 Desafios: Tarefas que demandavam mais esforço repetitivo, quando executadas em pares, geraram desmotivação dos membros mais experientes do Scrum Team. Como exemplo são citadas: a geração de relatórios, criação de scripts para tarefas relacionadas a banco de dados e configurações de servidor. Nestes casos, manter o pareamento se mostrou um desafio para estes membros, porém, seguiu válido, no momento que permitiu a disseminação do conhecimento com os membros inexperientes.

\subsection{Prontidão para Colaboração}

6.3.1 Adaptações: A criação, na ferramenta Discord, de canais específicos para colaboração entre o time, além da utilização da planilha de trabalho em par, abrangendo todas as pessoas, independente dos seus turnos de trabalho, colaboraram para o fomento de um ambiente propício à cooperação e colaboração. As próprias circunstâncias da 
implementação do trabalho remoto traduzem em uma maior prontidão para colaboração, visto que não havia alternativa para trabalho colaborativo presencial.

6.3.2 Framework Analítico: Segundo BJØRN et al. (2014), a comunicação informal contribui para promover a colaboração e a coordenação de atividades. Assim, os canais de socialização permitiram a comunicação informal e espontânea entre os membros da COTIC para troca de conhecimento, feedbacks e para minimizar, na medida do possível, o estresse e a sensação de isolamento causados pela pandemia.

6.3.3 Desafios: O uso intensivo de ferramentas de comunicação, gerou inquietação no time em relação às solicitações fora do horário de trabalho e a grande quantidade de mensagens. Encontrar um balanço entre as demandas da vida profissional e pessoal ainda é um desafio no contexto do trabalho remoto, especialmente durante a pandemia.

\subsection{Prontidão para Tecnologia de Colaboração}

6.4.1 Adaptações: Considerando-se a inserção de novas ferramentas colaborativas na rotina da COTIC e dos stakeholders, tornou-se necessário realizar um treinamento de preparação ao trabalho remoto e a criação de canais de auxílio e suporte às ferramentas, a fim de promover a prontidão para a tecnologia de colaboração.

6.4.2 Framework Analítico: Para OLSON e OLSON (2000), o desalinhamento na adoção e suporte das ferramentas é um dos maiores inibidores da adoção bem-sucedida de tecnologias colaborativas. Sendo assim, o treinamento oferecido permitiu orientar os stakeholders externos à COTIC sobre o trabalho remoto, explicando as dinâmicas a serem adotadas em cada atividade do processo, assim como oferecer instruções de configurações necessárias para a utilização das ferramentas colaborativas.

6.4.3 Desafios: Problemas relacionados à estabilidade e qualidade da conexão de internet foram identificados, gerando impactos no andamento das atividades em conjunto. Alguns membros do time também tiveram dificuldade pois, não possuíam equipamentos computacionais adequados para a execução do trabalho remoto em casa. Em alguns casos foi preciso dividir o computador com outras pessoas da família, em outros, o equipamento era de baixa capacidade para o ideal desempenho das suas atividades.

\subsection{Gestão Organizacional}

6.5.1 Adaptações: A COTIC teve liberdade para adaptar seu processo de trabalho de maneira autônoma do restante da organização. No contexto da pandemia, a alta gestão apoiou a escolha da metodologia de trabalho, das ferramentas colaborativas a serem utilizadas e do gerenciamento da carga horária de trabalho dos colaboradores.

6.5.2 Framework Analítico: Aspectos organizacionais são reconhecidos como importantes para criar condições que possibilitem a colaboração (BJØRN et al. 2014). Diante disso, as práticas ágeis utilizadas antes da pandemia foram mantidas, porém, adaptadas ao contexto de trabalho remoto. A adaptação envolveu a adoção de ferramentas colaborativas que permitiram manter a comunicação diária entre os membros do time. A flexibilidade na carga horária de trabalho também permitiu a liberdade do time em escolher o horário mais adequado para execução das suas tarefas, além de permitir que pessoas que atuavam em períodos diferentes no trabalho presencial tivessem agora a oportunidade de trabalhar juntos para a execução de tarefas em pares. 
6.5.3 Desafios: A alta gestão continuou enviando demandas com os prazos e metas estipulados no planejamento estratégico realizado antes da pandemia. Assim, estas pressões externas causaram aumento de tensão no time. Também se percebeu que, provavelmente devido à mudança para o trabalho remoto ter sido feita de maneira súbita, a organização não forneceu orientação padronizada para o time, o que demandou algum tempo de adaptação, principalmente para os colaboradores menos experientes.

\section{Discussão}

Neste trabalho observou-se que as atividades do processo de software da COTIC e os responsáveis pela execução destas se mantiveram inalterados. As principais modificações ocorridas foram a rápida adoção de ferramentas colaborativas para a execução das atividades e a realização de tarefas usando tais ferramentas. Em particular, a atividade Executar Sprint requereu diversos novos canais de comunicação e coordenação de atividades. Conforme visto na seção anterior, as modificações podem ser explicadas através dos conceitos do framework de colaboração distribuída de OLSON e OLSON (2000). Como estes resultados foram estruturados de acordo com este framework, esta seção será organizada da mesma forma.

No que diz respeito ao entendimento comum, as ferramentas colaborativas escolhidas permitem feedbacks rápidos e compartilhamento de informações para apoiar o trabalho remoto. OLSON e OLSON (2000) já tratavam da importância dessas ferramentas, relatando também as limitações tecnológicas da época, como a baixa qualidade do áudio e vídeo que limitavam o entendimento do que é dito e a identificação de quem estava falando. Entretanto, tais desafios estão menos presentes atualmente (BJØRN et al., 2014). Porém, desafios relacionados à riqueza da comunicação ainda impactam o entendimento comum (Watson-Manheim e Bélanger, 2002): comunicações em videoconferência foram mais bem-sucedidas do que aquelas que apenas utilizaram áudio. Em contrapartida, as condições de acesso a essas tecnologias precisavam de maior atenção, pois limitações relacionadas a infraestrutura e capacidade dos equipamentos do time e a instabilidade de suas conexões dificultaram reuniões em videoconferência. Assim, a falta de infraestrutura adequada e do apoio da gestão organizacional para resolver esta questão prejudicaram o entendimento comum.

Em relação ao acoplamento do trabalho foi observada uma dicotomia nos resultados entre desenvolvedores com diferentes níveis de experiência. Para aqueles mais experientes, a execução em grupo de tarefas de menor complexidade e de maior esforço repetitivo pode ser desgastante devido ao trabalho adicional necessário para execução dessas atividades fortemente acopladas de maneira similar ao relato de BJØRN et al. (2014). Já para colaboradores menos experientes, essa prática é importante para minimizar a curva de aprendizagem e facilita o compartilhamento de conhecimento entre os membros (OLSON e OLSON, 2000). De qualquer forma, não se observou uma redução no acoplamento das tarefas, mas, como esperado, uma transferência das mesmas para o ambiente digital com a adoção de ferramentas colaborativas.

No que diz respeito à prontidão para colaboração, os canais de comunicação criados nas ferramentas colaborativas foram percebidos positivamente pelo time. De maneira similar, FORD et al. (2020) relataram que interações espontâneas e informais, como por exemplo a hora do café virtual, eram muito apreciadas. A sala de "café virtual" também foi relatada por OLIVEIRA JR et al. (2020) como forma de socialização ou 
solicitação de apoio na busca por soluções no desenvolvimento de software. Por outro lado, elas também ocasionaram problemas, neste caso, interrupções como relatado por MACHADO et al. (2020).

Em relação à prontidão para tecnologia de colaboração, foram realizadas reuniões de preparação ao trabalho remoto e disponibilizados canais de suporte para os colaboradores. A importância da preparação do ambiente para o trabalho remoto também foi relatada nos trabalhos de CALDEIRA et al. (2020), BAO et al. (2020) e FORD et al. (2020). Recomendações de incentivos financeiros para aquisições de pacotes de internet, estações de trabalho e periféricos adequados para o trabalho remoto, assim como mobiliário ergonômico foram expressivas. A necessidade desses incentivos também já foi destacada em outros artigos relacionados (FORD et al., 2020; RALPH et al., 2020).

Finalmente, pode-se observar que grande parte das recomendações de melhorias relatadas na literatura referente ao trabalho remoto durante a pandemia do COVID-19 (FORD et al., 2020; RALPH et al., 2020; MACHADO et al., 2020) são centradas na dimensão de gestão organizacional. Se tais recomendações forem executadas, elas tem o potencial de impactar positivamente as outras dimensões do framework de colaboração distribuída. Na próxima seção, propomos recomendações para organizações e indivíduos trabalhando de forma remota em uma situação de crise.

\section{Recomendações}

Esta seção visa oferecer recomendações práticas organizadas de acordo com as cinco dimensões para colaboração distribuída de OLSON e OLSON $(2000,2008)$. Um resumo das recomendações é apresentado na Tabela 1.

Primeiro, para facilitar o entendimento comum, recomenda-se que as reuniões entre os membros do time sejam realizadas por videoconferência, com a câmera ligada, pois reuniões com vídeo permitem que os envolvidos possam utilizar gestos e as expressões faciais como forma de obtenção de feedback e consciência do estado de seus colegas de trabalho (se estão surpresos, tristes, focados, estressados, felizes, etc).

Do ponto de vista de acoplamento do trabalho, recomenda-se possibilitar o desacoplamento do trabalho para tarefas específicas especialmente aquelas repetitivas e de menor esforço intelectual. Porém, essas atividades devem ser documentadas para orientação de outros membros do time. Com esta prática de gestão do conhecimento, os membros mais experientes podem manter o foco nas tarefas de maior complexidade que exigem mais interação e alinhamento com os demais membros do time.

Em relação a prontidão para colaboração, não se trata apenas de melhorar as ferramentas e processos, mas também há a necessidade de orientação da organização em relação à manutenção de um equilíbrio entre a vida profissional e pessoal. Especificamente, recomenda-se que a flexibilidade da carga horária de trabalho, assim como o uso das ferramentas colaborativas fora do horário de expediente, devam ser limitadas para evitar sobrecarga e também para incentivar um estilo de vida saudável.

Em relação a prontidão para tecnologias colaborativas, sugere-se que a alta gestão reconheça a importância de apoio financeiro para possibilitar um bom ambiente de trabalho, com aquisições de pacotes de internet, estações de trabalho e periféricos adequados, assim como mesas e cadeiras para um ambiente de trabalho ergonômico. 
Finalmente, do ponto de vista de gestão organizacional, sugere-se deixar transparente para alta gestão a complexidade existente na comparação da produtividade com o período pré-pandemia evitando-se a cobrança excessiva que desconsidera o cenário como um todo. A exemplo da empresa GitLab, que elaborou um "Manual de Trabalho Remoto" (FORD et al., 2020), recomenda-se a elaboração e disseminação entre os stakeholders de um guia de práticas próprio da organização para transição ao trabalho remoto de casa. Este documento deve conter as diretrizes organizacionais para esta situação, assim como dicas sobre o uso adequado das ferramentas colaborativas. Recomenda-se também, manter a utilização da Wiki na ferramenta GitLab para centralização de dicas e informações relevantes sobre as etapas de execução das tarefas.

\section{Tabela 1 - Resumo das recomendações}

\begin{tabular}{|l|l|}
\hline \multicolumn{1}{|c|}{ Dimensões } & \multicolumn{1}{c|}{ Recomendações } \\
\hline Entendimento Comum & - Reuniões realizadas por videoconferência, porém com a câmera ligada. \\
\hline Acoplamento de Trabalho & $\begin{array}{l}\text { - Possibilitar o desacoplamento do trabalho para tarefas específicas que } \\
\text { sejam repetitivas e de menor esforço intelectual; } \\
\text { - Uso de ferramentas para gestão do conhecimento. }\end{array}$ \\
\hline Prontidão para Colaboração & $\begin{array}{l}\text { - Orientar colaboradores sobre equilíbrio entre a vida profissional e pessoal; } \\
\text { - Possibilitar a flexibilidade na carga horária de trabalho. }\end{array}$ \\
\hline Prontidão para Tecnologias & $\begin{array}{l}\text { - Apresentar à alta gestão a importância de apoio financeiro para } \\
\text { fornecimento de um bom ambiente de trabalho (infraestrutura física e } \\
\text { lógica). }\end{array}$ \\
\hline Golaborativas & $\begin{array}{l}\text { - Disseminar entre os stakeholders um guia de práticas para transição ao } \\
\text { trabalho remoto. Este guia deve conter as diretrizes organizacionais e dicas } \\
\text { para o uso adequado das ferramentas colaborativas e as etapas das tarefas } \\
\text { do processo; } \\
\text { - Apresentar à gestão a complexidade de se manter a produtividade em uma } \\
\text { crise e que a pressão excessiva pode gerar um ambiente desagradável entre } \\
\text { os colaboradores. }\end{array}$ \\
\hline
\end{tabular}

\section{Conclusão}

Este trabalho apresentou as adaptações realizadas no processo de trabalho de uma coordenação de tecnologia de uma pró-reitoria de uma universidade brasileira para a transição ao trabalho remoto devido a pandemia de COVID-19. Estas adaptações foram analisadas criticamente de acordo com os cinco conceitos para colaboração distribuída de OLSON e OLSON (2000). Também foram apresentados desafios encontrados durante esta transição e que ainda precisam ser abordados, especialmente em situações de crise. Finalmente, o artigo apresentou recomendações para a adaptação ao trabalho remoto.

Este trabalho apresenta limitações tanto de escopo (uma única equipe), como de metodologia visto que a participação ativa de um dos autores deste trabalho na equipe pode ter inserido algum viés nas ações observadas dos membros do time. De um modo geral, estas ações foram observadas através de registros digitais das atividades. Finalmente, deve-se mencionar que a COTIC realizou mudanças em seu processo de software em Janeiro de 2020 e o trabalho remoto iniciou em Março de 2020. Assim, é possível que esta mudança tenha influenciado alguns dos resultados aqui apresentados.

Como trabalhos futuros, diversas variações deste cenário podem ser estudadas a fim de validar os resultados desta pesquisa. Por exemplo, após a implantação das melhorias apontadas, uma nova pesquisa pode ser conduzida para verificar se os desafios identificados inicialmente foram endereçados ou se novos surgiram. Finalmente, seria 
interessante considerar o quanto as adaptações no processo de software foram efetivas do ponto de vista de produtividade para o contexto e time observado.

\section{Agradecimentos}

Cleidson R. B. de Souza agradece o apoio financeiro do CNPq (311256/2018- 0) nesta pesquisa.

\section{Referências}

Agile Manifesto. Disponível em $<$ http://agilemanifesto.org/>. Acesso em 10 de janeiro de 2021.

Aguiar, F.; Caroli, P. Product Backlog Building: Concepção de um Product Backlog evetivo. $1^{a}$ edição. São Paulo, Editora Caroli, 2020.

Bao, L.; et al. How dows Working from Home Affect Developer Productivity? A Case Study of Baidu During COVID-19 Pandemic. 2020. doi: arXiv:2005.13167

Bjørn, P.; et al. Does Distance Still Matter? Revisiting the CSCW fundamentals on Distributed Collaboration. ACM TOCHI 21, 5 (2014), 1-26.

Caldeira, C.; et al. Remote workers' wellbeing in the age of COVID-19.

Caroli, P. Lean Inception: Como alinhar pessoas e construir o produto certo. $1^{\text {a }}$ edição. São Paulo, Editora Caroli, 2018

Fino, C.M.N., 2003. FAQs, etnografia e observação participante. Revista europeia de etnografia da educação, 3, pp.95-105.

Ford, D.; Storey, M.; A Tale of Two Cities: Software Developers Working from Home During the COVID-19 Pandemic. 2020. doi: arxiv.org/abs/2008.11147

GitLab. The remote playbook from the largest all-remote Company in the world. 2020. Acesso em $<$ https://about.gitlab.com/resources/downloads/ebook-remote-playbook.pdf $>$.

Machado, L.; Gendered experiences of software engineers during the COVID-19 crisis. In IEEE Software, 2020. doi: 10.1109/MS.2020.3040135

Monteiro, L. T. and Oliveira, S. R. B. An Improvement on the Agile Process of COTICPROEG from UFPA to Attend MR-MPS-SW Process of Requirements Development. In: $16^{\text {th }}$ International Conference on Information System \& Technology Management, 2019.

OliveiraJr, E.; et al. Surveying the impacts of COVID-19 on the perceived productivity of Brazilian software developers. In Brazilian Symposium on Software Engineering, 2020.

Olson, G. M. and Olson, J. S. Distance Matters. Human-Computer Interaction 15, 2-3 (2000), 139-178.

Olson, J. S.; Hofer, E.; et al. (2008). A theory of remote scientific collaboration. Scientific collaboration on the internet, pp. 73-97.

Ralph, P.; Baltes, S.; Adisaputri, G. et al. Pandemic Programming. Empirical Software Engineering 25, 6 (2020), 4927-4961.

Scrum Guide. Acesso em $<$ https://www.scrumguides.org/docs/scrumguide/v2020/2020Scrum-Guide-PortugueseBR-2.0.pdf>.

Watson-Manheim, M. B., \& Bélanger, F. (2002). Support for communication-based work processes in virtual work. E-Service, 1(3), 61-82. 